\section{Immunoisolation of Centrosomes from Drosophila melanogaster}

The isolation of centrosomes from cells has been, for a long time, a challenging task. The main reason is that this small organelle $(\sim 0.3 \mu \mathrm{m}$ in diameter in mammalian cells) is present only in a single copy in the cell and therefore represents only a minuscule part of the whole cell proteome. Another technical difficulty is that the density of this organelle $(\rho>1.32 \mathrm{~g} / \mathrm{ml})$ is too high for it to be purified in a continuous gradient using isopycnic density centrifugation. Hence, step-gradient centrifugation has been the method of choice for most of the isolation approaches used to date. Both Ficoll and sucrose density gradients, as well as a combination of the two, have been employed. Most recent methods use sucrose gradient centrifugation only. Density gradient centrifugation is followed by immunofluorescence assays, microtubule nucleation assays, or electron microscopy to evaluate enrichment of cell organelles in particular fractions of the gradient.

Currently, isolation of centrosomes from Drosophila embryos, although relatively inefficient (i.e., only $\sim 10 \%$ of total centrosomes present in starting material are isolated), results in some of the best total yields compared to isolation of centrosomes from other organisms. In short, this method permits production of excellent quantities for many biochemical, functional, and structural studies.

The method described here focuses on the isolation of centrosomes from the syncytial stages of the early Drosophila embryo (0 to $3.5 \mathrm{hr}$ ). This has the particular advantage that cell organelles are not bounded by cellular membranes and that lysis can be performed on a relatively small scale, keeping the resulting volume low. This is an essential factor for subsequent gradient centrifugation steps, because ultracentrifugation of large buffer volumes is impractical. The abundance of pericentriolar material of these centrosomes isolated from the highly mitotic embryos produces excellent total protein yields. Moreover, maintenance of large fly populations that produce grams of starting material within a few hours is relatively cost efficient.

Basic Protocol 1 describes isolation of centrosomes from early-syncytial-stage Drosophila embryos by sucrose step gradient centrifugation. Basic Protocol 2 details an immunomagnetic isolation procedure for further purification of the centrosomes isolated in Basic Protocol 1. Support Protocol 1 details an immunofluorescence microscopy procedure for quantitatively tracking the gradient purification of centrosomes, and, finally, Support Protocol 2 describes fluorescence microscopy to assess the purification of the immunomagnetically isolated centrosome preparations.

\section{ISOLATION OF CENTROSOMES FROM THE EARLY SYNCYTIAL STAGES OF THE DROSOPHILA EMBRYO USING SUCROSE STEP GRADIENT CENTRIFUGATION}

This protocol outlines the production of Drosophila embryo extract as starting material for the isolation of centrosomes. Embryos are homogenized in homogenization buffer (HB), centrifuged at low speed, and filtered twice to remove large aggregates of membranes, debris, and other cell organelles. The two consecutive low-speed centrifugations also eliminate the large quantities of lipids that float on top of the embryo extract; these lipids need to be carefully removed to avoid contamination in subsequent isolation steps. The first two steps of density centrifugation serve to pool centrosomes for the subsequent immunoisolation, rather than to enrich cell organelles in a particular fraction. The

Contributed by Verena Lehmann, Hannah Müller, and Bodo M.H. Lange

Current Protocols in Cell Biology (2005) 3.17.1-3.17.13

Copyright (C) 2005 by John Wiley \& Sons, Inc.
UNIT 3.17

BASIC

PROTOCOL 1

Subcellular

Fractionation and Isolation of Organelles

3.17.1

Supplement 29 
affinity-isolation step then removes contaminants that copurify in the sucrose gradient to obtain a high degree of purity.

This protocol was adapted from Moritz et al. (1995) and Moritz and Alberts (1999) for use with the immunoisolation protocols developed by the authors of this unit.

\section{Materials}

Large population of Drosophila (e.g., $\sim 250,000$ strain W118 flies) maintained in large environmental incubator or temperature- and humidity-controlled room with fixed day (12 hr) and night (12 hr) cycles (Greenspan, 1997; Bonte and Becker, 1999; Sullivan et al., 2000)

Apple juice/molasses agar plates (see recipe)

Yeast paste: ordinary baker's yeast dissolved in warm water to form a paste

Embryo wash: $0.7 \%$ (w/v) NaCl/0.04\% (v/v) Triton X-100

$3 \%(\mathrm{v} / \mathrm{v})$ sodium hypochlorite in embryo wash (see above)

Homogenization buffer (HB, see recipe)

Liquid $\mathrm{N}_{2}$

$5 \times$ BRB80 with $100 \mathrm{mM} \mathrm{KCl}$ (see recipe), diluted to $1 \times$

$25 \%$ (v/v) Triton X-100

$100 \times$ protease inhibitor mix (PIM, see recipe)

$55 \%$ and $70 \%(\mathrm{w} / \mathrm{v})$ sucrose solutions (see recipes)

Fine strainer

Filter unit fitted onto vacuum flask

Motor-driven Wheaton homogenizer with tight-fitting Teflon pestle (60-ml volume)

50-ml conical polypropylene centrifuge tubes

Refrigerated low-speed centrifuge

Miracloth (Calbiochem)

15-ml snap-cap polypropylene tubes for freezing and storage of supernatants

39-ml thin-walled polyallomer ultracentrifuge tubes (e.g., Beckman)

Large-volume ultracentrifuge (e.g., Beckman) with swinging-bucket rotor (e.g., Beckman SW 32)

Additional reagents and equipment for assessing purify of centrosome fractions from gradient (see Support Protocol 1)

\section{Homogenize embryo material}

1. Collect 30 to $50 \mathrm{~g}$ of 0 - to 3.5 -hr-old Drosophila embryos by placing a fresh apple juice/molasses agar plate with a lump of yeast paste on the surface into the population cage every $3 \mathrm{hr}$.

Depending on the size of the fly population, three collections of $3 \mathrm{hr}$ each will be needed in order to obtain a total of $\sim 30$ to $50 \mathrm{~g}$ of embryo material.

2. After the 3-hr collection period for each plate, wash embryos off the plate with embryo wash using a paint brush to aid in removing the embryos, collecting them in a fine strainer, and store the embryos in ice-cold embryo wash until all embryos have been collected.

3. Remove the chorion layer by stirring embryos for $3 \mathrm{~min}$ in $250 \mathrm{ml}$ of $3 \%$ sodium hypochlorite solution.

4. Intensively wash the embryos with a forceful stream of cold tap water, then three times with a total volume of 1 liter of ice-cold distilled, deionized water, on a filter unit fitted onto a vacuum flask. Determine the dry weight after removing all excess water.

5. Resuspend dechorionated embryos in $\mathrm{HB}$ at a ratio of 1:5 (w/v).

\subsection{2}


6. Homogenize material on ice using five strokes of the motor-driven Wheaton homogenizer at a speed of $1500 \mathrm{rpm}$ in a cold room.

CAUTION: Wear protective gloves and goggles when using the homogenizer.

\section{Remove lipids and prepare/store HSS}

7. Transfer homogenate to 50-ml conical polypropylene centrifuge tubes. Centrifuge $10 \mathrm{~min}$ at $1800 \times \mathrm{g}, 4^{\circ} \mathrm{C}$. Remove floating lipids by aspirating with a suction pump and filter supernatant through Miracloth. Repeat the centrifugation, lipid removal, and filtration a second time.

8. Divide the resulting supernatant (referred to as HSS: i.e., "homogenate, supernatant, supernatant") into 10-ml aliquots in 15-ml conical polypropylene tubes, snap-freeze in liquid nitrogen, and store at $-80^{\circ} \mathrm{C}$ until further use.

The extract can be conveniently frozen at this stage if the isolation procedure must be interrupted. Freezing also gives the opportunity to produce stockpiles of embryo extracts without affecting the functional and structural integrity of the centrosome.

\section{Perform sucrose-gradient purifications}

9. Prepare six 50-ml conical polypropylene centrifuge tubes, each containing:

$20 \mathrm{ml} 70 \%(\mathrm{w} / \mathrm{v})$ sucrose

$1 \mathrm{ml} 1 \times \mathrm{BRB} 80$ with $100 \mathrm{mM} \mathrm{KCl}$

$640 \mu \mathrm{l} 25 \%$ Triton X-100

$400 \mu \mathrm{l} \mathrm{100 \times \text {PIM. }}$

10. Drop the contents of each $15-\mathrm{ml}$ tube containing a frozen 10-ml HSS aliquot into one of the 50-ml tubes containing the mixture prepared in the previous step, and thaw on ice. Collect a 30- $\mu \mathrm{l}$ aliquot for immunofluorescence microscopy (see below).

11. For each of the extract mixtures prepared in the previous step, pour a sucrose gradient in a 39-ml thin-walled polyallomer ultracentrifuge tube by carefully overlaying $3 \mathrm{ml}$ of $70 \%$ sucrose solution with $4 \mathrm{ml}$ of $55 \%$ sucrose, and, finally, at the top, the HSS mixture from the preceding step. Mark the upper margin of the 55\% sucrose layer of the sucrose gradient on the plastic wall of the tube.

12. Centrifuge samples for $1.5 \mathrm{hr}$ at $100,000 \times g$ in a SW 32 rotor with slow acceleration and slow braking.

Slow acceleration and braking correspond to "setting 4" on the Beckman instrument.

13. Aspirate the supernatant above the marked line with a vacuum aspirator. Pool the gradients (all of the sucrose solutions below the mark; Pool 1) and discard the pellets. Take a 30- $\mu$ l sample for immunofluorescence microscopy.

14. Dilute the $\sim 35$ to $40 \mathrm{ml}$ Pool 1 to $70 \mathrm{ml}$ with $1 \times$ BRB80 containing $100 \mathrm{mM} \mathrm{KCl}$ and add $100 \times$ PIM to a final concentration of $1 \times$.

15. Prepare two sucrose gradients in 39-ml thin-walled polyallomer tubes ultracentrifuge tubes by carefully overlaying $3 \mathrm{ml}$ of $70 \%$ sucrose solution with $1 \mathrm{ml}$ of $55 \%$ sucrose solution. Split the diluted Pool 1 (step 14) into two equal portions, and carefully overlay each of these portions over the $55 \%$ sucrose layer in each of the two respective tubes. Mark the upper margin of the 55\% sucrose layer of the sucrose gradient on the plastic wall of the tube.

16. Ultracentrifuge the gradients $1 \mathrm{hr}$ at $100,000 \times g, 4^{\circ} \mathrm{C}$. Remove the supernatant from each tube with a vacuum aspirator and discard the pellets. Pool the sucrose gradients (resulting in Pool 2). Take a 30- $\mu$ l sample for immunofluorescence microscopy.

Subcellular

Fractionation and Isolation of Organelles

\subsection{3}

Supplement 29 
SUPPORT PROTOCOL 1
Immunoisolation of Centrosomes
17. Assess the sample aliquots from each purification stage by immunofluorescence microscopy (see Support Protocol 1). Use the remainder of Pool 2 for further purification by immunoisolation (Basic Protocol 2).

In principle, these enriched preparations can also be used for functional in vitro microtubule nucleation assays and for standard immunofluorescence colocalization studies. However, the preparations are too crude to be used for biochemical analysis of centrosome composition. For convenience, samples can also be snap-frozen in liquid nitrogen until used in Basic Protocol 2.

\section{IMMUNOFLUORESCENCE MICROSCOPY OF ISOLATED CENTROSOMES}

This protocol is used to assess the enrichment and yield of aliquots from the intermediate steps in preparation of centrosomes.

\section{Materials}

30- $\mu$ l aliquots from Pool 1 and Pool 2 (see Basic Protocol 1)

PBS-T: phosphate-buffered saline (PBS; APPENDIX 2A), pH 7.4, containing $0.003 \%$ (v/v) Triton X-100

Methanol, $-20^{\circ} \mathrm{C}$

Primary antibody: anti- $\gamma$-tubulin (Sigma)

Secondary antibody: fluorochrome-conjugated antibody specific for $\mathrm{IgG}$ of the species from which the primary anti- $\gamma$-tubulin antibody was obtained

Mounting medium (e.g., Mowiol from Calbiochem, or 50\% v/v glycerol)

$20 \mathrm{mg} / \mathrm{ml}(10 \times) p$-phenylendiamine in $\mathrm{H}_{2} \mathrm{O}$

Nail polish

Plastic inserts to support a 11-mm round glass coverslip (Evans et al., 1985)

15-ml Corex tubes

11-mm round glass coverslips (grade 1)

Refrigerated centrifuge with swinging-bucket rotor (e.g., Sorvall HB-6 or Beckman JS 13.1, or equivalent) and adapters

24-well tissue culture plates

Spatula bent at the tip for removing the plastic insert

Needle with bent tip

Forceps

Microscope slides

Epifluorescence microscope equipped with immunofluorescence filters and appropriate optics

NOTE: To avoid staining artifacts, never allow the coverslips to dry out at any point during the following protocol.

\section{Centrifuge centrosome sample onto coverslip}

1. Resuspend the 30- $\mu \mathrm{l}$ aliquot of Drosophila centrosomes from HSS mix Pool 1 or Pool 2 in $11 \mathrm{ml}$ PBS-T.

Keep samples on ice until centrifugation.

2. Place a pair of plastic inserts into a $15 \mathrm{ml}$-Corex glass tube to support a $11-\mathrm{mm}$ round glass coverslip.

3. Transfer the 11-ml diluted centrosome sample into a 15-ml Corex tube and centrifuge onto the coverslips for $15 \mathrm{~min}$ at $15,000 \times g, 4^{\circ} \mathrm{C}$.

4. Remove the coverslip by lifting the top insert out of the Corex tube with a spatula bent at the tip. Transfer the coverslip with a pair of forceps immediately into $-20^{\circ} \mathrm{C}$ methanol in a well of a 24-well tissue culture plate and incubate at least $5 \mathrm{~min}$ at $-20^{\circ} \mathrm{C}$ to fix the sample. 
5. Aspirate methanol and rehydrate sample in the well by covering with $1.5 \mathrm{ml}$ PBS-T and incubating $15 \mathrm{~min}$ at room temperature. Aspirate PBS-T.

\section{Stain with antibodies}

6. Add $\sim 80 \mu \mathrm{l}$ of the anti- $\gamma$-tubulin primary antibody, appropriately diluted in PBS-T (e.g., 1:400 for polyclonal antisera, depending on antibody used), to each coverslipcontaining well. Incubate $1 \mathrm{hr}$ at room temperature in a moist environment.

7. Wash four times, each time by filling the sample-containing well(s) with an excess (e.g., $1.5 \mathrm{ml}$ ) of PBS-T, incubating $2 \mathrm{~min}$ at room temperature, and aspirating the solution.

Apply the PBS along the wall of each well and not directly onto the sample, to avoid rinsing the centrosomes away.

8. Add $\sim 80 \mu \mathrm{l}$ of the fluorophore-labeled secondary antibody diluted in PBS-T according to the manufacturer's recommendations to each coverslip-containing well. Incubate $45 \mathrm{~min}$ at room temperature in the dark in a moist environment.

The antibody dilution will vary; e.g., anti-mouse IgG whole-molecule dilutions will range between 1:400 and 1:2000.

\section{Mount coverslip on slide and examine centrosome preparation}

9. Remove coverslip(s) from well(s) with a bent needle and a pair of forceps and dip each coverslip briefly in water to rinse off excess PBS.

Coverslips can more easily be removed from the plastic wells using a needle with a slightly bent tip.

10. Add $20-\mathrm{mg} / \mathrm{ml}$-phenylenediamine to the mounting medium (e.g., Mowiol or $50 \%$ glycerol) for a final concentration of $1 \mathrm{mg} / \mathrm{ml}$. Mount each coverslip on a microscope slide with $6 \mu \mathrm{l}$ of the phenylenediamine-containing mounting medium. Carefully remove excess mounting medium with tissue, and allow to set for $20 \mathrm{~min}$ at room temperature in the dark. Seal with nail polish.

11. Check preparations under a fluorescence microscope or store at $4^{\circ} \mathrm{C}$ in the dark until samples are viewed.

The centrosomes should be homogenous in size and shape, and should be enriched through each step of the isolation procedure.

\section{IMMUNOPURIFICATION OF CENTROSOMES WITH MAGNETIC BEADS}

Prepare magnetic beads cross-linked with affinity-purified anti- $\gamma$-tubulin antibody. For negative control, magnetic beads are cross-linked with the relevant preimmune antibody. Centrosomes should be well enriched and quite similar in size. A ratio of 1:6 (v/v) between beads and centrosomes is recommended.

\section{Materials}

Protein $\mathrm{G}$ magnetic bead suspension (Dynal)

Phosphate-buffered saline (PBS; APPENDIX 2A)

$0.2 \mathrm{M}$ triethanolamine, $\mathrm{pH} 8.2$, with and without $20 \mathrm{mM}$ dimethyl pimelidate dihydrochloride (DMP); prepare fresh

Anti- $\gamma$-tubulin antibody (anti-peptide antibody; not commercially available; affinity-purified; Tavosanis et al., 1997)

Tris. Cl, pH 7.5 (APPENDIX 2A)

PBS (APPENDIX 2A) containing $0.1 \%(\mathrm{v} / \mathrm{v})$ Tween 20

PBS (APPENDIX 2A) containing 0.1\% (v/v) Tween 20 and $0.02 \%(\mathrm{w} / \mathrm{v})$ thimerosal

Pool 2 of centrosomes (see Basic Protocol 1)

Dilution buffer (see recipe), $4^{\circ} \mathrm{C}$ 
PBS-T: phosphate-buffered saline (PBS; APPENDIX 2A), pH 7.4, containing $0.003 \%$

(v/v) Triton $\mathrm{X}-100,4^{\circ} \mathrm{C}$

Methanol, $-20^{\circ} \mathrm{C}$

SDS sample buffer (UNIT 6.1)

Magnetic particle collector (magnet and magnetic stand) suitable for 1.5-ml microcentrifuge tubes (e.g., Dynal)

End-over-end rotator

Additional reagents and equipment for SDS-PAGE (UNIT 6.1) and determining purity of centrosome preparations from immunomagnetic purification (see Support Protocols 1 and 2)

\section{Prepare the antibody-coated magnetic beads}

1. Place $120 \mu \mathrm{l}$ of protein $\mathrm{G}$ magnetic bead suspension in a $1.5-\mathrm{ml}$ microcentrifuge tube. Place the tube on the magnetic stand to immobilize the beads with the magnet according to the manufacturer's documentation, and remove the supernatant. Add $100 \mu \mathrm{l}$ of PBS, resuspend the beads, and immobilize the beads on the magnet again. Repeat this wash four times.

2. Remove the supernatant and add $100 \mu \mathrm{g}$ of anti- $\gamma$-tubulin antibody to the washed protein $\mathrm{G}$ beads. Incubate $45 \mathrm{~min}$ on an end-over-end rotator at room temperature. Immobilize beads and remove supernatant.

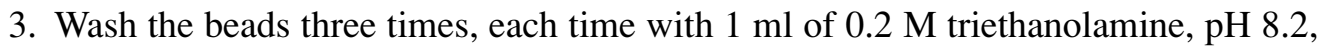
by immobilizing the beads on the magnet.

4. Cross-link by incubating the antibody-coupled beads with $1 \mathrm{ml}$ of freshly prepared $0.2 \mathrm{M}$ triethanolamine, $\mathrm{pH} 8.2$, containing $20 \mathrm{mM}$ DMP, on an end-over-end rotator at room temperature for $30 \mathrm{~min}$.

5. Place tube on the magnetic stand and remove supernatant. Add $1 \mathrm{ml}$ of $50 \mathrm{mM}$ Tris. $\mathrm{Cl}$, $\mathrm{pH} 7.5$, and incubate on an end-over-end rotator at room temperature for $15 \mathrm{~min}$.

6. Remove supernatant and wash beads three times, each time with $1 \mathrm{ml}$ PBS containing $0.1 \%$ Tween 20 , by immobilizing the beads on the magnet. Store antibody-coupled beads at $4{ }^{\circ} \mathrm{C}$ in the original bead-suspension volume of PBS containing $0.1 \%$ Tween 20 and $0.02 \%$ thimerosal.

Antibody binding and cross-linking efficiency can be checked by SDS-PAGE (UNIT 6.1) of 20- $\mu$ l samples of beads before and after cross-linking.

\section{Perform immunomagnetic separation}

7. Take $120 \mu \mathrm{l}$ antibody-coupled beads suspension and wash twice, each time with $1 \mathrm{ml}$ wash buffer using the technique described above. Take a sample of $20 \mu \mathrm{l}$ for later analysis by SDS-PAGE (UNIT 6.1).

8. Thaw $0.5 \mathrm{ml}$ of centrosome Pool 2 on ice, then mix with $0.5 \mathrm{ml}$ dilution buffer. Take a 20- $\mu 1$ sample for further analysis (see Support Protocol 1).

9. Add the $1 \mathrm{ml}$ of diluted centrosomes to $100 \mu \mathrm{l}$ washed, cross-linked beads. Mix gently by inverting the tube. Incubate $1 \mathrm{hr}$ at $4{ }^{\circ} \mathrm{C}$ on an end-over-end rotator. Immobilize the beads on the magnetic collector and carefully remove the supernatant. Keep the supernatant on ice for later analysis.

10. Wash beads three times, each time with $1 \mathrm{ml}$ cold wash buffer, using the technique described above.

11. Wash beads twice, each time with $1 \mathrm{ml}$ cold PBS-T, using the technique described above. Resuspend in $80 \mu \mathrm{l}$ (original bead volume) of PBS-T. Remove an aliquot of $10 \mu \mathrm{l}$ for immunofluorescence microscopy and an aliquot of $20 \mu \mathrm{l}$ for SDS-PAGE. 
12. Remove the PBS-T from the bead suspension with bound centrosomes $(50 \mu \mathrm{l})$, resuspend in 55\% sucrose solution, snap-freeze in liquid nitrogen, and store at $-80^{\circ} \mathrm{C}$.

The purified centrosome preparation is used subsequently in various assays. These include, for example, functional tests such as microtubule nucleation assay, electron microscopic study of centrosome morphology, antigen localization, or antigen for the generation of monoclonal or polyclonal antibodies, and biochemical assays.

13. Fix the 10- $\mu$ l aliquot of beads reserved for immunofluorescence microscopy for at least $5 \mathrm{~min}$ in $1 \mathrm{ml}$ of $-20^{\circ} \mathrm{C}$ methanol and store at $-20^{\circ} \mathrm{C}$ until analyzed according to Support Protocol 2.

\section{Assess purity}

14. Immobilize beads and remove supernatant as described above. Add SDS sample buffer, and boil 5 min. Perform magnetic collection to remove beads and run the supernatant on a 10\% SDS-PAGE gel (UNIT 6.1).

15. Assay diluted centrosome fractions before (see Support Protocol 1) and after immunomagnetic separation (see Support Protocol 2) by fluorescence microscopy.

\section{IMMUNOFLUORESCENCE MICROSCOPY OF IMMUNOPURIFIED CENTROSOMES ON MAGNETIC BEADS}

\section{Materials}

Centrosomes immunopurified on magnetic beads (see Basic Protocol 2)

Methanol, $-20^{\circ} \mathrm{C}$

PBS-T: phosphate-buffered saline (PBS; APPENDIX 2A), pH 7.4, containing $0.003 \%$ (v/v) Triton X-100

Primary antibody: anti- $\gamma$-tubulin (Sigma)

PBS-T containing $0.1 \%(\mathrm{w} / \mathrm{v})$ bovine serum albumin (BSA)

Secondary antibody: fluorochrome-conjugated antibody specific for IgG of the species from which the primary anti- $\gamma$-tubulin antibody was obtained

Mounting medium: Mowiol (Calbiochem)

$20 \mathrm{mg} / \mathrm{ml}(10 \times) p$-phenylendiamine in $\mathrm{H}_{2} \mathrm{O}$

Clear nail polish

Magnetic particle collector (magnet and magnet stand) suitable for $1.5-\mathrm{ml}$ microcentrifuge tubes (e.g., Dynal)

End-over-end rotator

Microscope slides

Round coverslips (grade 1, $11 \mathrm{~mm}$ diameter)

Epifluorescence microscope equipped with immunofluorescence filters and appropriate optics

NOTE: Handle samples with care and avoid vigorous mixing or vortexing.

1. Fix a $10-\mu l$ magnetic bead-centrosome sample in $1 \mathrm{ml}-20^{\circ} \mathrm{C}$ methanol by incubating for at least $5 \mathrm{~min}$ at $-20^{\circ} \mathrm{C}$. Place the test tube containing the beads on the magnetic stand, immobilize the beads with the magnet as described in the manufacturer's documentation, and remove the supernatant.

2. Add $1 \mathrm{ml}$ PBS-T to the beads in the tube. Mix gently by inverting the tube, then incubate 15 min on an end-over-end rotator. Collect beads and remove supernatant as described above.

3. Dilute the anti- $\gamma$-tubulin primary antibody $1: 500$ in PBS-T containing $0.1 \%$ BSA. Add $300 \mu \mathrm{l}$ of the diluted primary antibody to the beads in the tube and mix gently

Subcellular

Fractionation and Isolation of Organelles

3.17.7 
by inversion. Incubate $1 \mathrm{hr}$ at room temperature with gentle rotation. Collect beads and remove supernatant as described above.

4. Wash beads four times, each time by immobilizing the beads on the magnet, removing the supernatant, resuspending the collected beads in $1 \mathrm{ml}$ PBS-T, then removing the supernatant.

5. Dilute the fluorochrome-conjugated secondary antibody appropriately in PBS-T containing $0.1 \%$ BSA. Add $300 \mu \mathrm{l}$ of the diluted secondary antibody to the beads in the tube and mix gently by inverting the tube. Incubate $45 \mathrm{~min}$ at room temperature on an end-over-end rotator in the dark (cover tubes with aluminum foil). Collect beads and remove supernatant as described above.

6. Wash beads four times, each time with $1 \mathrm{ml}$ PBS-T using the technique described in step 4.

7. Add $20 \mathrm{mg} / \mathrm{ml} p$-phenylenediamine to Mowiol mounting medium for a final concentration of $2 \mathrm{mg} / \mathrm{ml}$. Add $\sim 30 \mu \mathrm{l}$ of this medium to the tube and mix gently by inverting the tube (solution is viscous).

8. Place $6 \mu \mathrm{l}$ of bead/Mowiol-mix on a microscope slide and carefully mount a coverslip on top. Let set for $\sim 20 \mathrm{~min}$ at room temperature in the dark. Seal the edges of the coverslip with nail polish.

9. Examine preparation under the epifluorescence microscope or store at $4^{\circ} \mathrm{C}$ in the dark until samples are viewed.

\section{REAGENTS AND SOLUTIONS}

Use deionized or distilled water in all recipes and protocol steps. For common stock solutions, SEe APPENDIX 2A; for suppliers, see SUPPLIERS APPENDIX.

\section{Apple juice/molasses agar plates}

For 200 plates:

11.5 liters $\mathrm{H}_{2} \mathrm{O}$

5 liters apple juice

$750 \mathrm{ml}$ molasses

$500 \mathrm{~g}$ agar

$420 \mathrm{ml} \mathrm{10 \%} \mathrm{(w/v)} \mathrm{Nipagin} \mathrm{(Fluka)} \mathrm{in} \mathrm{absolute} \mathrm{ethanol}$

\section{$B R B 80,5 x$}

To $100 \mathrm{ml} \mathrm{H}_{2} \mathrm{O}$ add:

$24.2 \mathrm{~g}$ PIPES (400 $\mathrm{mM}$ final)

$2 \mathrm{ml} 0.5 \mathrm{M}$ EGTA (5 mM final)

$1 \mathrm{ml} 1 \mathrm{M} \mathrm{MgCl}_{2}$ (5 mM final)

Adjust $\mathrm{pH}$ to 6.8 with $\mathrm{KOH}$ pellets.

Add $\mathrm{H}_{2} \mathrm{O}$ to $200 \mathrm{ml}$

Store up to 2 months at $4{ }^{\circ} \mathrm{C}$

\section{Dilution buffer}

To $200 \mathrm{ml}$ phosphate-buffered saline (PBS; APPENDIX 2A) add:

$0.4 \mathrm{~g}$ bovine serum albumin (BSA, fraction $\mathrm{V} ; 0.2 \% \mathrm{w} / \mathrm{v}$ final)

$100 \times$ protease inhibitor mix (see recipe) to $2 \times$ final

$20 \mathrm{mg} / \mathrm{ml}$ stock of DNase I, RNase free to final concentration of $20 \mu \mathrm{g} / \mathrm{ml}$ (stock stored at $-20^{\circ} \mathrm{C}$ )

Prepare fresh just prior to use 


\section{Homogenization buffer}

To $140 \mathrm{ml} \mathrm{H}_{2} \mathrm{O}$ add:

$40 \mathrm{ml} 5 \times$ BRB80 $(1 \times$ final $)$

$20 \mathrm{ml} 1 \mathrm{M} \mathrm{KCl}$ (100 mM final)

$28 \mathrm{~g}$ sucrose $(14 \% \mathrm{w} / \mathrm{v}$ final)

$100 \times$ protease inhibitor mix (see recipe) to $2 \times$ final

Prepare fresh

\section{Protease inhibitor mix (PIM), 100x}

To $3 \mathrm{ml}$ of methanol add:

$4 \mathrm{ml}$ of $1 \mathrm{mg} / \mathrm{ml}$ aprotinin (dissolved in $\mathrm{H}_{2} \mathrm{O}$ )

$4 \mathrm{ml}$ of $1 \mathrm{mg} / \mathrm{ml}$ leupeptin (dissolved in $\mathrm{H}_{2} \mathrm{O}$ )

$4 \mathrm{ml}$ of $1 \mathrm{mg} / \mathrm{ml}$ pepstatin A (dissolved in methanol)

$5 \mathrm{ml}$ of $100 \mathrm{mg} / \mathrm{ml}$ Pefabloc SC (Roche; dissolved in $\mathrm{H}_{2} \mathrm{O}$ )

Store up to 2 weeks at $-20^{\circ} \mathrm{C}$

\section{Sucrose solution, $55 \%(w / v)$}

To $140 \mathrm{ml} \mathrm{H}_{2} \mathrm{O}$ add:

$40 \mathrm{ml} \mathrm{5 \times} \mathrm{BRB80}(1 \times$ final $)$

$20 \mathrm{ml} 1 \mathrm{M} \mathrm{KCl}(100 \mathrm{mM}$ final)

$110 \mathrm{~g}$ sucrose $(55 \% \mathrm{w} / \mathrm{v}$ final)

Store up to 2 months at $4{ }^{\circ} \mathrm{C}$

Sucrose solution, $70 \%(w / v)$

$40 \mathrm{ml} 5 \times$ BRB80 buffer $(1 \times$ final $)$

$20 \mathrm{ml} 1 \mathrm{M} \mathrm{KCl}(100 \mathrm{mM}$ final $)$

$140 \mathrm{~g}$ sucrose $(70 \% \mathrm{w} / \mathrm{v}$ final)

$\mathrm{H}_{2} \mathrm{O}$ to $200 \mathrm{ml}$

Heat without boiling to dissolve

Store up to 2 months at $4{ }^{\circ} \mathrm{C}$

\section{Wash buffer}

To $200 \mathrm{ml}$ phosphate-buffered saline (PBS; APPENDIX 2A), add:

$0.2 \mathrm{~g}$ bovine serum albumin (BSA, fraction $\mathrm{V} ; 0.1 \% \mathrm{w} / \mathrm{v}$ final)

$100 \times$ protease inhibitor mix (see recipe) to $1 \times$ final

$20 \mathrm{mg} / \mathrm{ml}$ stock of DNase I, RNase free to final concentration of $20 \mu \mathrm{g} / \mathrm{ml}$ (stock stored at $-20^{\circ} \mathrm{C}$ )

Prepare fresh just prior to use

\section{Yeast Paste}

For 90 plates:

$220 \mathrm{ml} \mathrm{H}_{2} \mathrm{O}$

$150 \mathrm{~g}$ baker's yeast

$1.4 \mathrm{ml}$ propionic acid (Merck)

\section{COMMENTARY}

\section{Background Information}

Protocols for the isolation of centrosomes from higher eukaryotic cells are classically based on cell organelle enrichment via gradient centrifugation. Various successful protocols have been described that isolate centrosomes from mammalian tissue cul- ture cells (Mitchison and Kirschner, 1986; Bornens et al., 1987; Blomberg-Wirschell and Doxsey, 1998; Bornens and Moudjou, 1999), tissue (Komesli et al., 1989; Lange and Gull, 1995), clam oocytes (Palazzo and Vogel, 1999), Drosophila (Moritz and Alberts, 1999; Lange et al., 2000), and yeast
Subcellular Fractionation and Isolation of Organelles 
(Wigge et al., 1998), to mention only some of the more frequently used sources. Most of the employed methods involve a lysis step in a low-ionic-strength buffer followed by density gradient centrifugation. The material thus produced is used subsequently in various assays. These include functional tests such as microtubule nucleation assay, electron microscopic study of centrosome morphology, antigen localization, or antigen production for the generation of monoclonal or polyclonal antibodies. Furthermore, centrosomal preparations have been used for the characterization of protein content of the organelle (protein complex); this application requires preparations in which the centrosomes are both highly enriched and present in biochemically meaningful quantities-i.e., micrograms of centrosomes for subsequent gel electrophoresis and mass spectrometry analysis (Wigge et al., 1998; Lange et al., 2000; Andersen et al., 2003).

\section{Critical Parameters and Troubleshooting}

\section{Lysis and homogenization}

Correct lysis and homogenization are critical for yield as well as for purity of centrosome preparations. Alternative methods using either tissue or mammalian tissue culture cells as starting material carry out the lysis in a low-ionic-strength buffer. Pretreatment of cells with anti-actin (e.g., cytochalasin B) and anti-microtubule drugs (e.g., nocodozole) has been employed in order to release the nuclear-centrosome interaction; this technique was initially proposed to efficiently dissociate the centrosome from the cytoskeleton and nuclei. However, cytochalasin treatment might not be an essential prerequisite for cytoskeletal dissociation (Bornens and Moudjou, 1999). Here, for Drosophila lysis and homogenization, buffer conditions are derived from the classical PIPES-based microtubule reassembly buffer (BRB80) but are modified (Moritz and Alberts, 1999) to include additional salt and sucrose, probably bringing them closer to isotonic conditions. An additional condition determining the outcome of the preparations is the efficient removal of the outer protective chorion layer of Drosophila embryos using washes with sodium hypochlorite solution. Incomplete removal can cause blockage or overheating of the tight-fitting Teflon pestle and render the material produced nearly useless.
Isolation of centrosomes by density gradient centrifugation

In the protocol developed by Moritz and Alberts (1999) for the isolation of Drosophila centrosomes, cell organelles are enriched in a single sucrose step gradient. The isolated centrosomes have been used in structural assays (electron microscopy) and functional assays (in vitro microtubule nucleation). Here centrifugation is carried out in two consecutive rounds, which represent concentration steps rather than purifications. These steps are then followed by affinity immunoisolation of centrosomes to remove co-migrating contaminants. Other groups employ, albeit for mammalian centrosome isolation, Ficoll gradients in a concentration step (Michison and Kirschner, 1986) or a rapid isolation step (Blomberg-Wirschell and Doxsey, 1998). This step can be followed by a purifying sucrose gradient centrifugation. The gradient is then fractionated and assayed by immunofluorescence microscopy using an anti- $\gamma$-tubulin antibody (Support Protocol 1) to select for the most enriched fractions for subsequent experiments. In the protocol in this unit, this assay is used to calculate the yield and determine the quality of isolated organelles. To perform this calculation, the number of centrosomes per relative area of the coverslip are counted, i.e., a given volume of the preparation is centrifuged down onto the coverslip, the count is performed, and the results extrapolated to the total volume of the preparation. A similar assay, though based on electron microscopy negative staining, can also be employed for rapidly checking the quality and structural integrity of centrosome preparations (Lange and Gull, 1996).

\section{Purification of centrosomes by immunoaffinity purification}

Because the avenue of density banding of centrosomes is blocked due to the high density of the organelle, the purity of most of the current centrosome isolation protocols is limited. Therefore, the authors of this unit developed a protocol for the affinity purification of centrosomes. The critical parameter here is the quality of the antibody that is used for the immunoprecipitation. Each antibody will need to be tested to determine if the antibody will or will not work under certain buffer or detergent concentrations and antibody concentrations, and protocols will have to be adapted accordingly. The initial protocol for affinity isolation 

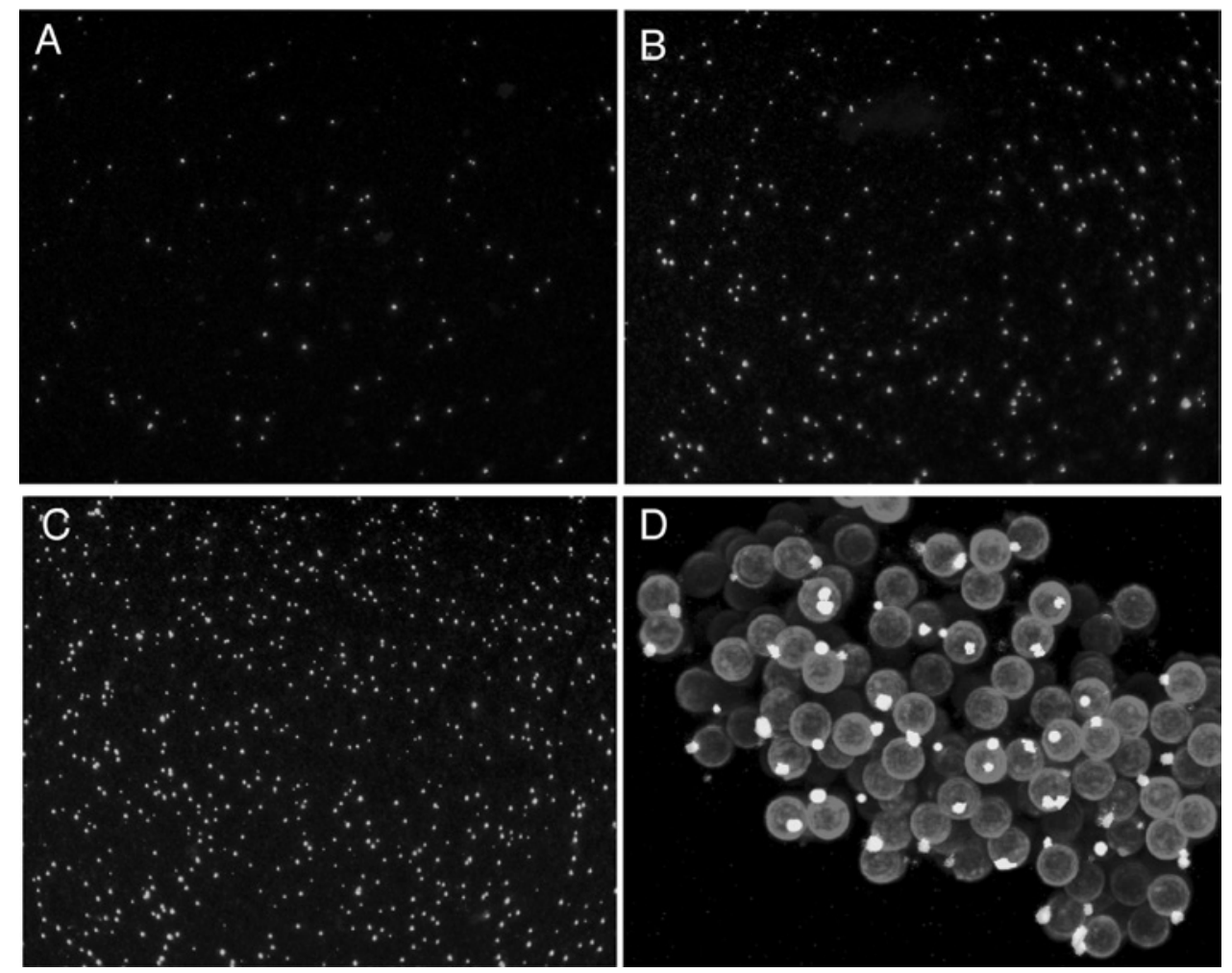

Figure 3.17.1 These images show the consecutive isolation steps assayed by immunofluorescence microscopy (Support Protocols 1 and 2) using an anti- $\gamma$-tubulin antibody to evaluate number and integrity of isolated centrosomes. (A) Centrosomes in embryo homogenate; (B) Pool 1; (C) Pool 2; (D) immunopurified centrosomes. Centrosomes are shown in yellow, beads are shown in red. For the color version of this figure go to http://www.currentprotocols.com.

of centrosomes was based on an indirect affinity method (Lange et al., 2000). In this technique, centrosomes were first coated with antibody, then anti-immunoglobulin beads were employed to isolate the centrosomes in a second step. In the protocol described in this unit, the authors use direct coupling of antibodies to magnetic beads to affinity purify centrosomes from enriched sucrose gradient fractions. This reduces the number of steps involved and consequently improves the yield.

\section{Anticipated Results}

With the described method microgram quantities of centrosomal protein can easily be obtained from $\sim 10 \mathrm{~g}$ of embryo extract. Centrosomes should be intact as assayed by immunofluorescence microscopy (Support Protocols 1 and 2) and electron microscopy (Lange and Gull, 1996). Immunofluorescence images of centrosomes from consecutive isolations steps labeled with an anti- $\gamma$-tubulin antibody (see Fig. 3.17.1, panels A to D) are quantified to control enrichment and yield. In the Coomassie-stained SDS-PAGE analysis (see Fig. 3.17.2) of the immunopurified preparations, a major band should be $\mathrm{CNN}$, a centrosomal protein of about $130 \mathrm{kD}$ (see Fig. 3.17.2, asterisk) indicating the level of enrichment of the preparations.

\section{Time Considerations}

In well maintained fly populations, large quantities of embryo material can be obtained almost on a daily basis. Collection of material and production of embryo extract can be streamlined so that extracts are stockpiled for future use. The actual preparation of centrosomes by density gradient centrifugation can be easily achieved within $4 \mathrm{hr}$, and samples can be safely frozen without losing microtubule nucleation activity. Affinity purification, including all of the washing and coupling steps, will consume $\sim 4 \mathrm{hr}$, not taking into account buffer and antibody preparation time. Assays monitoring the quality of the
Subcellular Fractionation and Isolation of Organelles

\subsubsection{1}

Supplement 29 


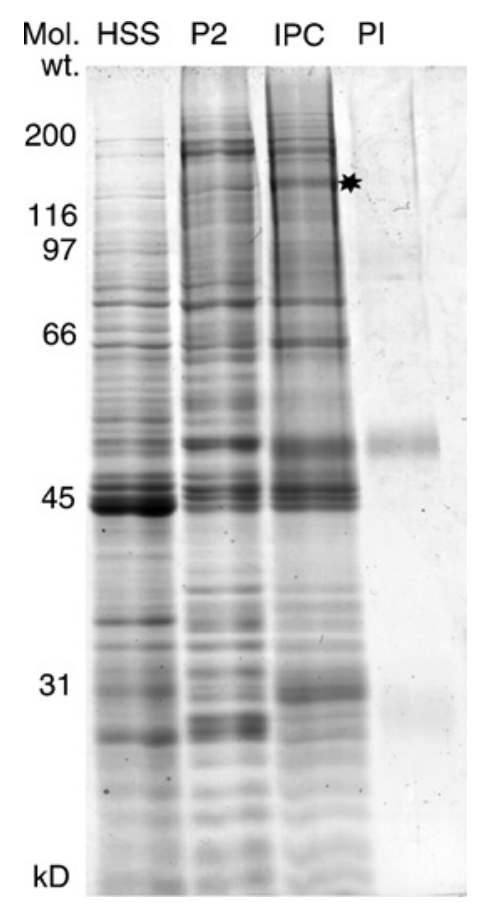

Figure 3.17.2 Isolation profile showing the protein composition of samples from the major consecutive steps in a Coomassie-stained gel. Abbreviations: HSS, homogenate supernatant supernatant; P2, Pool 2; IPC, immunopurified centrosomes; PI, preimmune isolation negative control. The asterisk at $\sim 130 \mathrm{kDa}$ labels the position of one of the major centrosome components (CNN) that is enriched throughout the isolation process.

preparation using immunofluorescence microscopy and SDS-PAGE are performed within 3 to $4 \mathrm{hr}$, not including microscope viewing time. Most solutions can be made ahead of time and stored either at $4{ }^{\circ} \mathrm{C}$ or $-20^{\circ} \mathrm{C}$ as indicated. Some solutions, such as proteinase inhibitors and DNase, must be added fresh from stock solutions to the solutions prior to use.

\section{Literature Cited}

Andersen, J.S., Wilkinson, C.J., Mayor, T., Mortensen, P., Nigg, E.A., and Mann, M. 2003. Characterization of the human centrosome by protein correlation profiling. Nature 426:570574.

Blomberg-Wirschell, M. and Doxsey, S.J. 1998. Rapid isolation of centrosomes. Methods Enzymol. 298:228-238.

Bonte, E. and Becker, P.B. 1999. Preparation of chromatin assembly extracts from preblastoderm Drosophila embryos. Methods Mol. Biol. 119:187-194.

Bornens, M., Paintrand, M., Berges, J., Marty, M.C., and Karsenti, E. 1987. Structural and chemical characterization of isolated centrosomes. Cell Motil. Cytoskel. 8:238-249.

Bornens, M. and Moudjou, M. 1999. Studying the composition and function of centrosomes in vertebrates. Methods Cell Biol. 61:13-34.
Evans, L., Mitchison, T., and Kirschner, M. 1985. Influence of the centrosome on the structure of nucleated microtubules. J. Cell Biol. 100:11851191.

Greenspan, R.J. 1997. Fly Pushing: The Theory and Practice of Drosophila Genetics. Cold Spring Harbor Laboratory Press, Cold Spring Harbor, N.Y.

Komesli, S., Tournier, F., Paintrand, M., Margolis, R.L., Job, D., and Bornens, M. 1989. Mass isolation of calf thymus centrosomes: Identification of a specific configuration. J. Cell Biol. 109:2869-2878.

Lange, B.M.H. and Gull, K. 1995. A molecular marker for centriole maturation in the mammalian cell cycle. J. Cell Biol. 130:919-927.

Lange, B.M.H. and Gull, K. 1996. A structural study of isolated mammalian centrioles using negative staining electron microscopy. J. Struct. Biol. 117:222-226.

Lange, B.M.H., Bachi, A., Wilm, M., and Gonzalez, C. 2000. Hsp90 is a core centrosomal component and is required at different stages of the centrosome cycle in Drosophila and vertebrates. EMBO J. 19:1252-1262.

Mitchison, T.J. and Kirschner, M.W. 1986. Isolation of mammalian centrosomes. Methods Enzymol. 134:261-268

Moritz, M. and Alberts, B.M. 1999. Isolation of centrosomes from Drosophila embryos. Methods Cell Biol. 61:1-12. 
Moritz, M., Braunfeld, M.B., Fung, J.C., Sedat, J.W., Alberts, B.M., and Agard, D.A. 1995. Three-dimensional structural characterization of centrosomes from early Drosophila embryos. J. Cell Biol. 130:1149-1159.

Palazzo, R.E. and Vogel, J.M. 1999. Isolation of centrosomes from Spisula solidissima oocytes. Methods Cell Biol. 61:35-56.

Sullivan, W., Ashburner, M., and Hawley, R.S. (eds.) 2000. Drosophila Protocols. Cold Spring Harbor Laboratory Press, Cold Spring Harbor, N.Y.

Tavosanis, G., Llamazares, S., Goulielmos, G., and Gonzalez, C. 1997. Essential role for gammatubulin in the acentriolar female meiotic spindle of Drosophila. EMBO J. 16:1809-1819.
Wigge, P.A., Jensen, O.N., Holmes, S., Soues, S., Mann, M., and Kilmartin, J.V. 1998. Analysis of the Saccharomyces spindle pole by matrixassisted laser desorption/ionization (MALDI) mass spectrometry. J. Cell Biol. 141:967-977.

Contributed by Verena Lehmann,

Hannah Müller, and Bodo M.H. Lange Max Planck Institute for Molecular Genetics

Berlin, Germany
Subcellular Fractionation and Isolation of Organelles

3.17.13 